\section{kompakt}

\section{Macht Passivrauchen Kinder taub?}

Machen quarzende Eltern ihre Kinder taub? Zumindest schlechter hörten die 1533 untersuchten Jugendlichen (12-19 Jahre) einer Studie, wenn sie den Nikotinmetaboliten Cotinin im Blut hatten - und zwar doppelt so häufig wie nichtexponierte Kinder. Als Ursache vermuten die Forscher Durchblutungsstörungen im Innenohr.

Arch Otolaryngol Head Neck Surg. 2011, 137:655

\section{Selbsterdrosselung durch Massagegerät}

Erdrosslung statt Entspannung: die amerikanische Zulassungsbehörde FDA warnt vor dem „ShoulderFlex Massager" einer US-Firma, der über ebay auch hierzulande erhältlich ist. Die FDA weiß von einem Todessowie einem Beinahetodesfall durch das einer Nackenrolle ähnelnde Gerät, das in der Mitte eine rotierende Stange enthält. Eigentlich ist diese zwar von einem Tuch überdeckt, aber wenn es dumm läuft, können sich trotzdem Schmuck oder Kleidung des auf dem Gerät liegenden Anwender verfangen, sodass aus der geplanten Shiatsu-Massage eine Strangulation wird. Meldung FDA 26.08.2011

\section{Krebstherapie mit Mutantenviren}

Genetisch veränderte onkolytische Pockenviren lassen sich möglicherweise für die systemische Krebstherapie nutzen. US-Forscher haben in einer Phase-I-Studie mit 23 Krebskranken ein Virus verwendet, das sich gezielt in Tumorzellen mit aktiviertem EGFR/ Ras-Signalweg vermehrt und die Zellen tötet. Nicht maligne Zellen blieben von den Viren unbehelligt. Bei einigen Patienten mit therapierefraktären soliden Tumoren ließ sich die Tumorprogression zumindest aufhalten. Nature 2011, 477:99

\title{
Kommissars Albtraum
}

\section{Kein Fingerabdruck? Da waren die Gene am Werk!}

Sie wird auch die „Einreiseverzögerungskrankheit" genannt und dürfte jeden Kriminellen erfreuen: Bei der Adermatoglyphie gibt es keine Fingerabdrücke. Forscher haben jetzt die Ursache hierfür gefunden: die Gene.

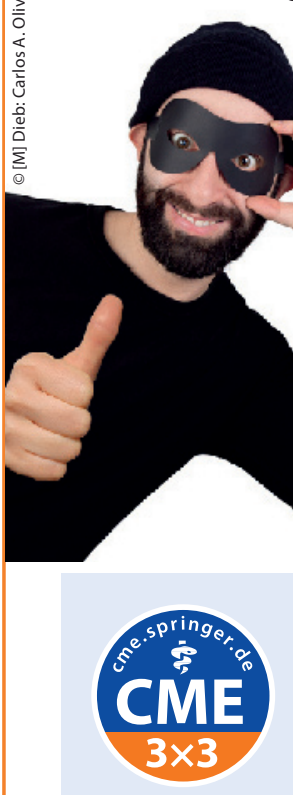

Wenn Menschen mit Adermatoglyphie ihre Finger erst ins Stempelkissen und dann aufs Papier d r ü cken, dürfte das nur einen schwarzen Unerkannt auch am Daumen? Das würde jeden Dieb erfreuen!
Klecks ergeben. Die sonst für jeden Menschen charakteristischen Epidermalleisten fehlen nämlich bei diesen Menschen.

Wie es dazu kommen kann, haben jetzt israelische Forscher entdeckt: Sie untersuchten die Mitglieder einer Familie, bei der mehrere Mitglieder fingerabdrucklos waren. Bei diesen fanden sie eine Genmutation, durch die ein die DNA-schädigendes Enzym produziert wird. Zum Glück macht sich dieser Defekt nur als Entwicklungsstörung in der Haut bemerkbar. Und so haben betroffene Patienten höchsten an Landesgrenzen Probleme, wenn man ihnen die krankhafte Ursache ihres „incognitos“ nicht glauben will. (sko) Nousbeck J et al, Am J Hum Genet 2011, 89:302

\section{CME-Punkte kostenlos in jeder Ausgabe}

\section{CME hilft Ihnen, Ihr Punktekonto zu füllen!}

Mit unseren drei zertifizierten Fortbildungen können Sie pro Heft auf CME.springer.de/CME kostenlos 9 Punkte sammeln. Und so geht's:

\section{Kostenlos teilnehmen in vier Schritten}

\section{Auswählen}

Wählen Sie online auf CME.springer. de/CME den Link zum aktuellen Heft aus. Entscheiden Sie nun, welche Fortbildungseinheiten Sie zum Erwerb von CME-Punkten nutzen wollen. Die Teilnahme an den drei Einheiten der aktuellen Ausgabe ist kostenlos.

\section{Registrieren/Anmelden} Sind Sie bereits bei CME.springer.de registriert? Dann genügt zur Anmeldung die Angabe Ihrer persönlichen Zugangsdaten. Falls Sie zum ersten Mal teilnehmen, bitten wir Sie, sich einmalig zu registrieren. Wir senden Ihnen dann per E-Mail Ihre persönlichen Zugangsdaten zu. Bitte benutzen Sie diese für alle weiteren Teilnahmen zur Anmeldung (Login).

\section{Teilnehmen}

Sie können die elektronische Version der Fortbildung online lesen, ausdrucken oder direkt die 10 CME-Fragen beantworten. Die kostenlose Teilnahme ist 3 Monate nach Erscheinen der Zeitschrift möglich.

\section{CME-Punkte sammeln} Nach erfolgreicher Beantwortung von 7 der 10 CME-Fragen senden wir Ihnen Ihre Teilnahmebestätigung samt Punkten umgehend per E-Mail zu. Diese können Sie bei Ihrer zuständigen Landesärztekammer einreichen. 